\title{
Design prototype of a smart household touch sensitive locker security system based on GSM technology
}

Mohammad Zeyad, Susmita Ghosh, S. M. Masum Ahmed

Departement of Electrical \& Electronic Engineering, American International University-Bangladesh, Bangladesh

\begin{tabular}{|c|c|}
\hline Article Info & ABSTRACT \\
\hline Article history: & This paper illustrates a portable domestic locker security system which is \\
\hline Received Dec 18, 2018 & $\begin{array}{l}\text { based on GSM (Global System for Mobile Communications) technology. A } \\
\text { handcrafted low-cost touch sensitive box is designed (using Vero board) for }\end{array}$ \\
\hline Revised Jan 26, 2019 & the project which is one of the most attractive features of the system. The \\
\hline Accepted Jul 5, 2019 & $\begin{array}{l}\text { system will operate in a way that if there is any unexpected user, tries to } \\
\text { touch any portion of the touch sensitive box, a feedback system will be }\end{array}$ \\
\hline Keywords: & $\begin{array}{l}\text { turned on immediately. The feedback system will alert the property holder } \\
\text { about the unexpected user by sending SMS (Short Message Service) and }\end{array}$ \\
\hline Alarm system & turning on an alarm system. The alarm system will be turned off only if it \\
\hline GSM & $\begin{array}{l}\text { receives a specific SMS from the property holder. This system not only has } \\
\text { the advantages of high sensitivity, small size and lightweight, but also it is }\end{array}$ \\
\hline Security system & easy to use. This system is featured with an uncomplicated design, \\
\hline Touch sensitive box & convenient use, strong flexibility and reliable performance. Since the circuit \\
\hline Vero board & $\begin{array}{l}\text { in the system is simple and easy to contrivance, the system can be installed } \\
\text { without any difficulty at homes \& offices. It will also provide a good security } \\
\text { in the vehicles and Automated Teller Machine (ATM) booths. }\end{array}$ \\
\hline
\end{tabular}

Copyright (C) 2019 Institute of Advanced Engineering and Science. All rights reserved.

\section{Corresponding Author:}

Susmita Ghosh, Departement of Electrical \& Electronic Engineering (EEE), American International University-Bangladesh (AIUB), 66/a Kuratoli, Kuril, Dhaka-1229, Bangladesh. Email: susmitaghosh29@gmail.com

\section{INTRODUCTION}

Nowadays, domestic security is one of the most significant \& conceivable issues for human being. Home security as well as domestic belongings security is a prime issue of concern because it is not only just about financial or monetary safety but also much more than that. Everyone wants the protection of their essential assets. This is the key reason why concept of locker security arises. Presently, the crime rate is swiftly increasing day by day. Every day we can see in the news that someone killed his mother for the girlfriend, a girl could be raped, a couple could be murdered, a family could be looted etc. This news becomes a common scenario in our society. Protecting home is one of the utmost importance. A great security system is needed for this purpose, to make an enormous difference for the safety of the user, his home, family and possessions. Installing a security system is the best path to keep our house safe even in the absence of the homeowner. The user can also use this feature whenever they are at home or abroad, sleeping, eating or traveling. With the help of smart security locker system, the user can keep a hawk's eye on the property.

This section Security is considered as a major issue for the home automation. Traditional techniques of alarm-based security have gained much popularity in past decades. During the recent past, several systems were introduced for security measurements based on wired networks. In literature, researchers suggested a number of security systems based on new technologies like GSM (Global System for Mobile Communication), GPRS (General Packet Radio Service), internet, ASICs (Application Specific Integrated 
Circuit), USN (Ubiquitous Sensors Network) and implemented through FPGA (Field Programmable Gate Arrays), DSP (Digital Signal Processor), and MCU (Memory Control Unit/Microcontroller Unit).

Installation and maintenance cost of a GSM based home security system is much cheaper than other home security system. It is also very flexible and durable. The great advantage of this system is not to be hacked because it involves only a mobile network. Besides, the users of the other GSM based security systems has to count money every day for each SMS. So, by simplifying the system, the researchers are trying to keep the installation and maintenance cost low. In the past, several SMS based home security systems were developed. Rozita, Ahmed, Chan and Hoong in [1], developed a full control home based automation system using a PIC16F887 microcontroller which was integrated with GSM module communicating at a baud rate of 9600 bps. In [2], microcontroller AT89C55 will be interfaced with a GSM module through RS-232 communication protocol for interaction between the users' mobile phone and the security system. Baris, Alper, Tosun, Kaan and Ali in [3], ex-plain the home automation system using GSM, internet and speech recognition. In these systems, the home gateway is internet based which requires a personal computer (PC). However, it's hard to manage PC and keep it $\mathrm{ON}$ all the time. Also, it consumes more power. Khandare and Mahajan in [4], where a GSM module was inter-faced with a desktop computer. Here, clients were connected to the computer through Wi-Fi access points and the home appliances have wired connection to the computer. Another such system was developed in [5], used a PIC18F452 microcontroller to monitor doors and windows of a home which could be accessed only by entering the proper ID.

A few years back, Inderpreet Kaur did a research entitled "Microcontroller Based Home Automation System with Security" and got an automated home could be used for simple grouping of controls where any appliance that is plugged into electrical power is remotely controlled [6]. Moreover, Ahmed ElShafee and Karim Alaa Hamed did another research entitled "Design and Implementation of a WiFi Based Home Automation System" and they had concluded their system could support a wide range of home automation devices like power management components, and security components as well [7]. Visa M. Ibrahim and Asogwa A. Victor had developed a design entitled "Microcontroller Based Anti-theft Security System Using GSM Networks with Text Message as Feedback". Particularly, in this paper, they had designed an anti-theft security system using an embedded system design with Dual Tone Multi-Frequency (DTMF) and a GSM to monitor as a safeguard for car [8]. Rozita Teymourzadeh and his team did a research on "Smart GSM based Home Automation System" and their final results show an accuracy of $\geq 98 \%$ with a maximum of four loads [9].

Jayashri Bangali and Arvind Shaligram did a research on Design and Implementation of Security Systems for Smart Home based on GSM technology and this research paper suggest two types of security system. One system had based on web camera another system had based on GSM technology [10]. Raqibull Hasan and his team designed a Microcontroller Based Home Security System with GSM Technology. A Compiler Code Vision AVR is used to design a program that controls the system along with maintaining all security functions [11]. Mohammad Amanullah "Microcontroller Based Reprogrammable Digital Door Lock Security System by Using Keypad \& GSM/CDMA Technology". In this system, a matrix keypad had used for a change it any time due to the password is stored in PROM. Besides, an IPS circuit had used for giving backup in case of an emergency when there is a power failure [12]. Zamshed Iqbal Chowdhury and his team did a research entitled with "Design and implementation of Pyroelectric Infrared sensor-based security system using microcontroller". Actually, in this paper, the development of a Low-cost security system using small PIR (Pyroelectric Infrared) sensor had built using microcontroller [13].

The system presented in this paper is a combination of GSM and MCU. GSM pro-vides wide coverage as GSM association estimates $90 \%$ of the global mobile market using GSM standard. The proposed system provides reliable security, effortless installation and portability. In this work once the system is programmed, neither computer nor internet connection are required, thus ensuring simplicity of use. In this paper, we present the theft prevention using a technological solution namely "Smart Household Touch Sensitive Locker Security System Based on GSM Technology". A locker (touch sensitive box) covered by touch plates is connected to the device. If the locker feels any unauthorized touch, an alarm system will be activated without any delay \& the owner will get a SMS from the server via GSM module to protect the locker. The categorization of this paper: Section-II describes about components used in the system, Section-II depicts the methodology of the system compiled of both hardware and software implementation, Section-IV holds the experimental results and Section- $V$ concludes the paper.

\section{EQUIPMENT FAMILIARIZATION}

The circuit is designed considering simplicity of uses. The overall system contains different functional units combined together, those interact with each other to provide the total functionality of a 
security system. The microcontroller and the GSM module will be chosen as the main components for designing the circuit. Other components like capacitors, resistors, buck converter, crystal oscillator, adapters, transistor etc. are also used to accomplish the design goal. The following equipment are main components of the system those are used to provide the total functionality.

\subsection{Microcontroller}

An 8-bit microcontroller called ATmega328p will be used in this project. It is a low-power microcontroller based on AVR enhanced RISC architecture. It is a 28-pin microcontroller. ATmega328p has $32 \mathrm{~KB}$ programmable flash memory and static RAM of $2 \mathrm{~KB}$. The ATmega328/P provides the following features: 32Kbytes of In-System Programmable Flash with Read-While-Write capabilities, 1Kbytes EEPROM, 2Kbytes SRAM, 23 general purpose I/O lines, 32 general purpose working registers, Real Time Counter (RTC), three flexible Timer/Counters with compare modes and PWM, 1 serial programmable USARTs , 1 byte oriented 2-wire Serial Interface (I2C), a 6-channel 10-bit ADC (8 channels in TQFP and QFN/MLF packages), a programmable Watchdog Timer with internal Oscillator, an SPI serial port, and six software selectable power saving modes [14]. The Arithmetic Logic Unit (ALU) is directly connected with all 32 registers. Although, allowing two independent registers to be accessed in one single instruction executed in one clock cycle. Achieving throughputs up to ten times faster than conventional CISC microcontrollers then the resulting architecture is more code efficient.

\subsection{Global system for mobile communication (GSM)}

SIM800L evaluation board will be used, which is controlled by the microcontroller ATmega328p. A SIM800L evaluation board is used to make the development process easier and faster. SIM800L is a quadband GSM/GPRS module, that works on frequencies GSM850MHz, EGSM900MHz, DSC1800Mhz and PCS1900MHz. SIM800L features GPRS multi-slot class 12/class 10 (optional) and supports the GPRS coding schemes CS-1, CS-2, CS-3 and CS-4 [15]. This is also a low power device which has a tiny size$15.8 * 17.8 * 2.4 \mathrm{~mm}$ which helps in putting it with a microcontroller on a breadboard in a small sized box to form our device. SIM800L can meet al-most all the space requirements in user applications, such as smart phone, PDA and other mobile devices.

\subsection{Buck converter}

The buck converter is an omnipresent DC-DC converter that effectively changes over a high voltage to a low voltage proficiently [16]. Proficient power transformation expands battery life, lessens warm, and takes into account littler contraptions to be built. The buck converter can be utilized as a part of heaps of cool applications. This article gives a concise prologue to the buck converter and spreads a couple of cool utilization of buck converter circuits and its cousin the half-bridge and gives connects to assets where intrigued per users can take in more about particular chips to use in their designs. The basic operation of the buck converter has the current in an inductor controlled by two switches (as a rule a transistor and a diode) [8]. In the glorified converter, every one of the parts is thought to be great. In particular, the switch and the diode have zero voltage drop when on and zero current stream when off, and the inductor has zero arrangement protection [17]. Further, it is accepted that the information and yield voltages don't change throughout a cycle (this would imply the output capacitance as being vast) [17].

\section{METHODOLOGY}

GSM plays a key role in the process of receiving and transmitting information in wireless security control networks that will affect the communication distance, node power consumption, network stability and other indicators directly.

\subsection{Hardware design of the system}

The entire system design is being divided into two parts- hardware implementation and software simulation. The hardware is designed according to the rules of the embedded system. The system is composed of three different units: The control unit, the alarm unit and the touch sensitive box. The latter is to make an inventive $\mathrm{C}$-code for programming the $\mathrm{MCU}$ and GSM module to monitor and control the secured environment.

- The control unit: it works together with the detection part and manages the alarm circuit to control the alarm function.

- The alarm unit: a buzzer is used to give an alarm.

- Touch sensitive box: A touch sensation sheet was designed by using Vero board to protect the objects which will not work until it feels any unauthorized touch. A detection circuit connected to

Design prototype of a smart household touch sensitive locker security system based ... (Mohammad Zeyad) 
the device which will detect an unexpected error and give an immediate signal to begin turn on the system. The general block diagram of the proposed system is shown in Figure 1.

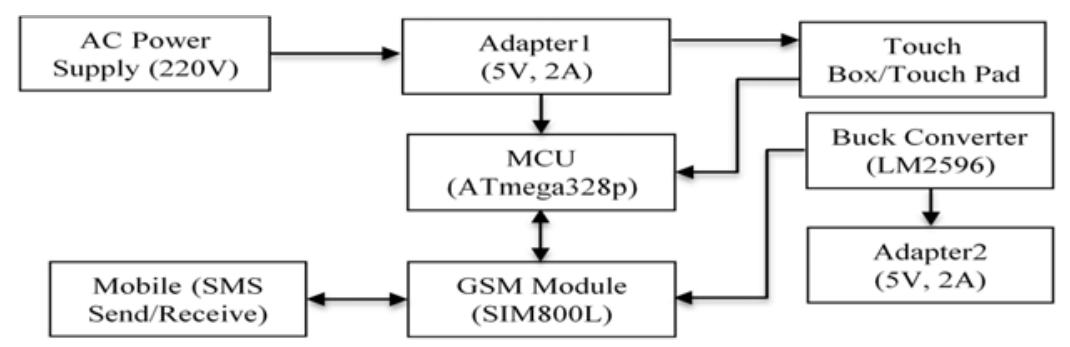

Figure 1. Block diagram of proposed system

\subsection{Working principle of the system}

A microcontroller is a self-contained system with peripherals, memory and a processor that can be used as an embedded system [18]. Most programmable microcontrollers that are used today are embedded in other consumer products or machinery including phones, peripherals, automobiles and household appliances for automated systems. Due to that fact, another name for a microcontroller is "embedded controller" [19]. Transmitting \& receiving functions can be done easily \& accurately by using microcontroller, so that design microcontroller-based technology SIM800L module is used to complete the proposed system. To accomplish the task, we controlled the device by using AT mega328p MCU.

Microcontroller is the most demanded programmable chip which is used for designing a home automated system [18]. To complete this hardware implementation, a microcontroller and two adapters $(5 \mathrm{~V}$, $2 \mathrm{~A}$ ) had used for the conversion of $220 \mathrm{~V} \mathrm{AC}$ to $5 \mathrm{~V}$ DC which is an appropriate voltage for a microcontroller [19]. Figure 2 shows the circuit diagram of proposed system.

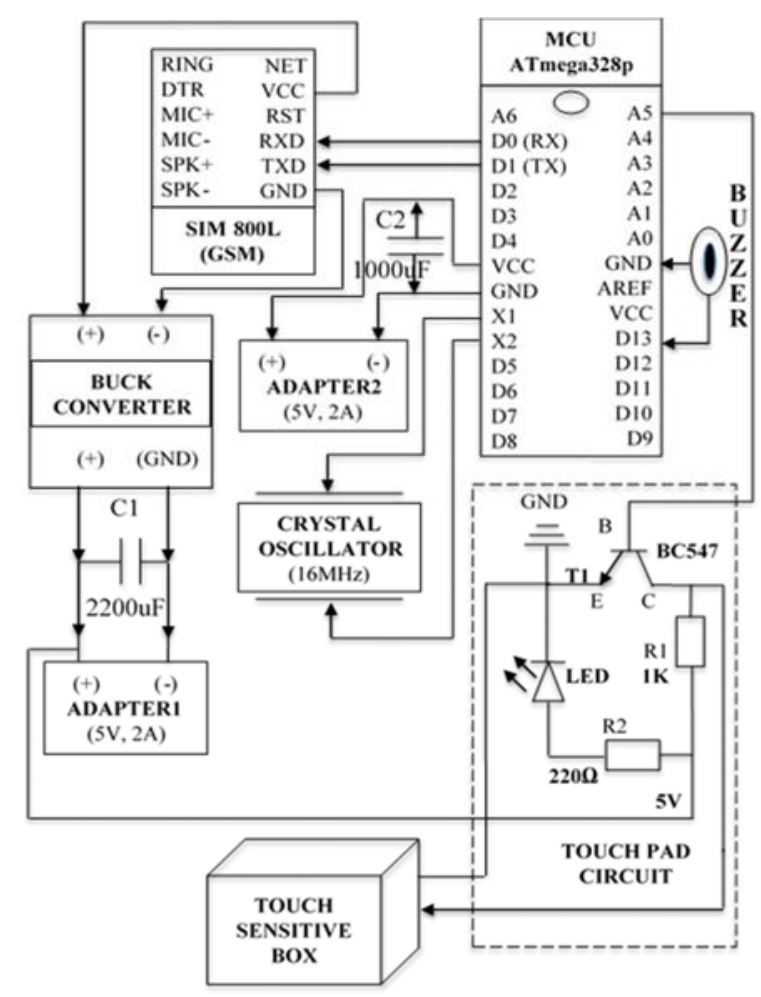

Figure 2. Circuit diagram of proposed system 
Firstly, at the time of running the circuit, some unexpected negative polarity was present in it. To reduce the negative polarity, a crystal oscillator had used which also reduced some voltage of the microcontroller as well. In Figure 1, the microcontroller is represented by 'MCU' which receives the command through an adapter $(5 \mathrm{~V}, 2 \mathrm{~A})$ for the conversion of $220 \mathrm{~V}$ AC to $5 \mathrm{~V}$ DC. The SIM800L module is represented by "GSM" which is an entire Quad-band GSM/GPRS arrangement in an SMT sort that can be inserted in the client applications [18]. A buck converter was used, because initially, some unexpected negative polarity was present in the circuit. Buck Converter is also connected with an adapter (5V, 2A) for the conversion of $220 \mathrm{~V} \mathrm{AC}$ to $5 \mathrm{~V}$ DC which is an appropriate voltage for the SIM800L module. This buck converter is responsible for the reduction of some voltage of the microcontroller as well [19]. A handmade touch sensitive box is connected with the MCU which helps to alert and notify through sending an SMS to the property holder by any unexpected users.

In this circuit, initially, $220 \mathrm{~V}$ AC is stepped down to $5 \mathrm{~V} \mathrm{DC}$ by using adapters. Two different value capacitors were used to energize the device. A handmade touch box circuit was connected with the A5 pin of the microcontroller. An alarm was rung and sent an alert message to the user through the microcontroller after receiving the earlier given instruction and the threshold value. The microcontroller and GSM module communicated with each other through USART communication. Figure 3 shows the schematic diagram of the touch box circuit of the proposed system.

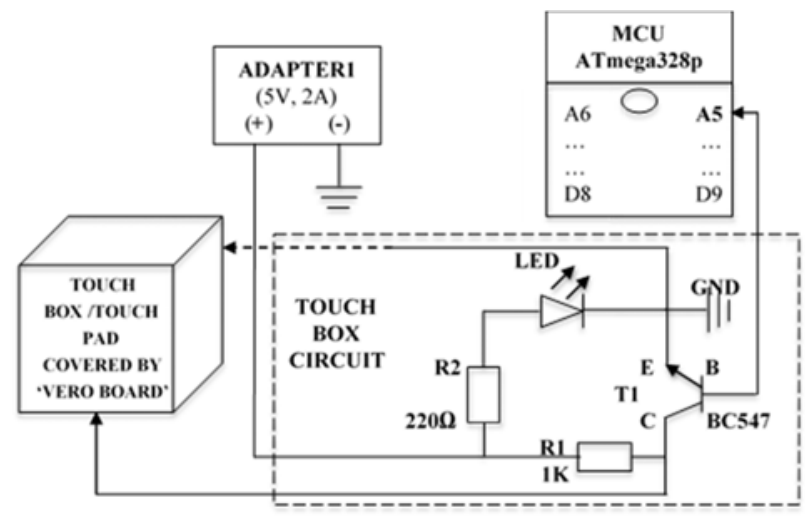

Figure 3. Schematic diagram of touch circuit operation

The microcontroller sends an SMS using the GSM module on the occurrence of two events: (a) when it feels any unauthorized touch, (b) receives an acknowledgment reply from the authorized user. Whenever the touch box detects unauthorized touch, the GSM module, buzzer alarm \& lights will be activated without any delay. The GSM module operates through the operating SIM and sends the SMS. Any instructions that come or go to the user will come to the module using the operating SIM number. The module then decodes the upcoming message from the user and sends commands according to the operating microcontroller. The microcontroller receives SMS through the GSM module and retrieves the new configuration settings from the SMS and saves the same in the microcontroller. The module also receives the signal from the operating microcontroller and sends the message to the user subsequently. So, the GSM module works as a bridge connector between the security system and the user.

A touch-sensitive box was designed to complete the work. There are many touch-pads, touch plates, metal plates are available in the market which are used for security scheme. But in order to make the system cost effective, we designed a handmade touch box for a smart domestic locker security system. The touch box circuit was designed considering low cost $\&$ the simplicity of uses. A Vero board had chosen as the main component for the touch box circuit design. Other components like an NPN transistor (BC547), two different value resistors (i.e. $\mathrm{R} 1=1 \mathrm{~K} \& \mathrm{R} 2=220 \Omega)$, a $\mathrm{LED}$, an adapter $(5 \mathrm{~V}, 2 \mathrm{~A})$ etc. are also used to accomplish the design goal. After proper verification on the breadboard, the design was transferred to a Vero board for a permanent construction. A box was made by the Vero board so that each module can be easily identified. Before proper soldering, a component plan was drawn to pay a particular attention for minimizing the distances between the points \& connections. After that, all other components were connected to implement the circuit. Finally, touch box circuit was connected to the A5 pin of ATmega328p. Thus, the touch box design was completed for smart domestic locker security system.

Design prototype of a smart household touch sensitive locker security system based ... (Mohammad Zeyad) 


\subsection{Software design of the system}

First of all, the system file was loaded into the ATmega328p. The system was initialized to implement the specific task, such as checking touch system, GSM communication and so on. After that, each module was reset to run commands. A touch sensing system was programmed in a graphical user interface using the $\mathrm{C}$ programming language. This program was used to control the GSM terminal. The alarm system will be activated on the failure of authentication. Alarm system was used to notify the presence of unauthorized user. When the alarm system will be turned on, an alert message will be sent to the locker owner regarding the presence of theft attempt. Alarm system will be deactivated only when it receives specified SMS from the authorized user otherwise system error will be there.

This process will be activated only when hardware and software chain are inter-connected. At first, the system will initialize the system clock. After that, the system will execute the system codes to open interrupting task. The whole system was built around a MCU. The MCU requires to be burned with software written for specific applications. The code was written using ASSEMBLY language and compiled using Arduino. Arduino generates a hex file which was burned using a burner into the IC. The touch box works simply as a switch for MCU. At the beginning of the program or during the healthy condition, the external interruption of the MCU remains disable. Therefore, any signal input on the pin A5 cannot generate an interruption. When there is no disturbance to the touch box, the box acts like an open circuit, the signal is LOW and when the disturbance occurs, the box works as the closed circuit, therefore the signal is HIGH on pin A5. The MCU repeatedly keeps on checking the switch status of the system.

MCU breaks out of the signal checking loop and waits for the switch to be closed. Whenever the input signal state is HIGH on A5, MCU interprets it as the true detection of motion of any unwanted body. In this case, MCU will turn on the alarm sys-tem and send proper AT commands to the GSM modem to initiate a SMS to a pre-defined number. After sending the SMS, MCU will wait for a pre-defined time before executing following instructions through the device owner. This wait state allows the SMS to be completed successfully. After that, MCU goes to SLEEP mode. Enabling the SLEEP mode ensures that MCU will wake up from the SLEEP mode whenever there is a LOW to HIGH transition on A5, i.e. when the switch gets opened. When an external interruption occurs, MCU wakes up from sleep mode and disable the external interruption and the program goes to the beginning of the algorithm. A flowchart represents the locker security system model in Figure 4.

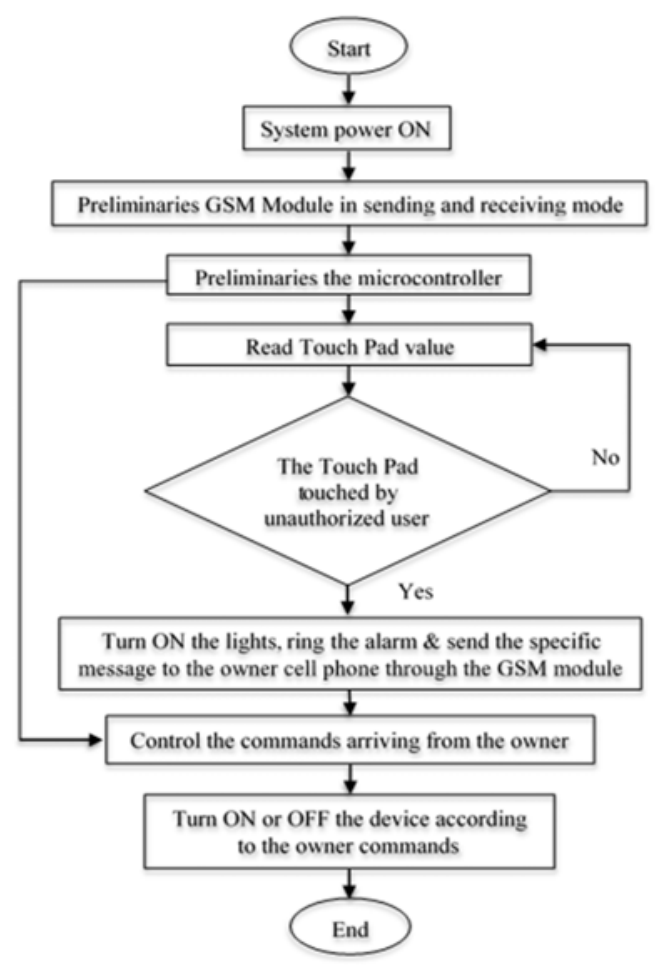

Figure 4. System acquisition flow chart

Int J Pow Elec \& Dri Syst Vol. 10, No. 4, Dec 2019 : 1923 - 1931 


\subsection{Implemented system}

This experiment mainly aims at domestic locker security system which plays an alarm sound to draw attention and at the same time, an alert message was sent to the locker owner by sensing touch based on the touch box. The system entity diagram had shown in Figure 5.

To operate the smart household locker security system, some accessible keywords had used which will help the user to access the GSM-based system by sending SMS from anywhere. Perhaps, to secure the system with non-observant people's different keywords can be used for different users personally.

Accessible keywords are:

\#a1 --- Buzzer, Light ON

\#a0 --- Buzzer, Light OFF

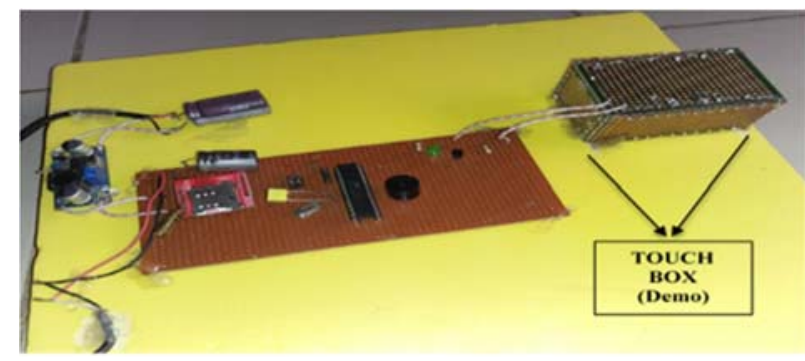

Figure 5. Schematic diagram of touch circuit operation

\section{EXPERIMENTAL RESULTS AND ANALYSIS}

During the $\mathrm{ON}$ mode of the device, device gained voltage and current. By using a Multimeter, we measured the voltage \& current for different circumstances. After finding the voltage \& current values, power consumption was calculated. If voltage, current \& power is denoted by V, I \& P respectively, then power formula is expressed as: $\mathrm{P}=\mathrm{VI}$ (1) [20]. Table 1 represents the Power Consumption of the system.

Table 1. System power consumption

\begin{tabular}{ccccc}
\hline Conditions No. & Voltage, V $(\mathrm{V})$ & Current, I (A) & Power, P (W) & Remarks \\
\hline 1 & 1.66 & 0.97 & 1.61 & When touch box not touched \\
2 & 4.95 & 1.91 & 9.45 & When touch box touched \\
3 & 4.99 & 1.96 & 9.78 & When touch box touched \\
\hline
\end{tabular}

To test the touch box circuit, we checked the correct power supply at TP1 with respect to TP0. When the touch box was not touched, the estimated frequency at TP2 was $1 \mathrm{kHz}$. This frequency disappeared when the touch box feels any unauthorized touch. Verified voltage levels are indicated in Table 2 at TP3 and TP4. Table 2 shows the System Feedback Data on different test point of the touch box.

Table 2. System feedback data

\begin{tabular}{cccc}
\hline Test point (TP) & Buzzer & $\begin{array}{c}\text { System feedback } \\
\text { GSM module }\end{array}$ & Remarks \\
\hline TP0 & Off & Off & 0V; GND \\
TP1 & Off & Off & $+5 \mathrm{~V}$ \\
TP2 & Off & Off & $1 \mathrm{kHz}$; when touch box not touched \\
TP3 & Off & Off & $0.6 \mathrm{~V} ;$ when touch box not touched \\
TP4 & Off & Off & OV; when touch box not touched \\
TP5 & On (Alarmed) & On (SMS sent through the system) & $+5 \mathrm{~V}$; when touch box touched \\
\hline
\end{tabular}

To control the mobile phone through its ports for the communication between mobile phone and GSM module, AT (AT is the abbreviation of ATTENTION) was used for commands, provided by the merchant companies. The GSM module was connected with MCU \& controlled by AT commands had known by us. Hence, AT commands were used to access and control the built-in commands of the mobile phone. Table 3 shows AT commands that are used in the proposed system.

Design prototype of a smart household touch sensitive locker security system based ... (Mohammad Zeyad) 
Table 3. System AT commands

\begin{tabular}{cc}
\hline AT command & Descriptions \\
\hline AT+CNMI & New SMS message indications \\
AT + CMGF & Select SMS message format \\
AT+CMGD & Delete unauthorized SMS \\
AT + CMGS & Send SMS to specific number \\
& (It's a security SMS from your asset. Please Check) \\
AT + CMGR & Read authorized SMS \\
AT + CMEE & To report mobile equipment error \\
\hline
\end{tabular}

\section{CONCLUSION}

This paper successfully implements a domestic security system based on emerging wireless technology, microcontroller and GSM. The system was used along with an android application to maintain security at any location through a panic-button. The system is intelligent enough to monitor the secure environment and let the user know about the security infringement. The remote user can control his premises from any part of the world through the GSM network. As GSM is a wireless technology, the user can get alerts anywhere in the world thus making the system independent of location. For instance, the owner is alerted through an SMS if any motion is detected in the touch box while the system was activated. MCU is programmed for the system and main part of it. AT commands will be used in the system to explore the services of mobile and control the services flexibly. The factors on which time is taken to send a message depends on the range of a specified network and its coverage area. For global communication, GSM module is used to communicate between the user and system. Traditional burglar alarm mode is also used to ensure reliability. The GSM communication provides worldwide coverage, easy, and a low-cost way of information interchange. The MCU provides interoperability of GSM and also makes this system portable and easy to install as the system is embedded and does not require computer once programmed. A handmade touch sensible circuit box had designed for the system which is the most attractive part of the system. Hence, the touch sensible circuit makes the device cost low. So, it can provide a low-cost, fast and reliable security service for any user to be used at their homes.

In this paper, it is shown that how an affordable, reliable home appliance controlling system can be implemented where the controlling is possible anywhere within the GSM coverage area. There is no need of an expert person to operate the system because the system is very easy to control. Additionally, it is possible to implement the whole system in iOS and Windows operating system as well. Since the whole system is done following the Android operating system. In the future, we will try to accommodate the biometric system and face recognition techniques for locking and unlocking the system in the proposed model. We are working on the project to expand it for complete building security and automation and also to interface it to the internet through Wi-Fi networks. The proposed system can be able to help the whole economic situation in any developing country if the system will be implemented in a larger field like banks, ATM booths, universities, restaurants, hotels, industries, garments and many more. Specially, the system will save some valuable time and reduce human efforts as well. It could be concluded that the proposed system considerably have more scopes for further research and development in the near future that makes the system more comfortable and user friendly.

\section{REFERENCES}

[1] Teymourzadeh R., Ahmed SA, Chan KW, and Hoong MV., "Smart gsm based home automation system," arXiv preprint arXiv:180603715. 2018.

[2] Elkamchouchi H. and ElShafee A., "Design and prototype implementation of SMS based home automation system," Electronics Design, Systems and Applications (ICEDSA), 2012 IEEE International Conference, 2012.

[3] Yuksekkaya B, Kayalar AA, Tosun MB, Ozcan MK, and Alkar AZ., "A GSM, internet and speech controlled wireless interactive home automation system," IEEE Transactions on Consumer Electronics, vol. 52(3), pp. 837-43, 2006.

[4] Khandare MS and Mahajan A., "Mobile monitoring system for smart home," Emerging Trends in Engineering and Technology (ICETET), 2010 3rd International Conference, 2010.

[5] Islam MS, "Home security system based on pic18f452 microcontroller," Electro/Information Technology (EiT), 2014 IEEE International Conference, 2014.

[6] Kaur I. Microcontroller based home automation system with security. International journal of advanced computer science and applications. 2010;1(6):60-5.

[7] ElShafee A, Hamed KA. Design and implementation of a WIFI based home automation system. World academy of science, engineering and technology. 2012;68:2177-80.

[8] Ibrahim VM, Victor AA. Microcontroller based anti-theft security system using GSM networks with text message as feedback. International Journal of Engineering Research and Development. 2012;2(10):18-22.

Int J Pow Elec \& Dri Syst Vol. 10, No. 4, Dec 2019: 1923 - 1931 
[9] Teymourzadeh R, Ahmed SA, Chan KW, Hoong MV, editors. Smart gsm based home automation system. 2013 IEEE Conference on Systems, Process \& Control (ICSPC); 2013: IEEE.

[10] Bangali J, Shaligram A. Design and Implementation of Security Systems for Smart Home based on GSM technology. International Journal of Smart Home. 2013;7(6):201-8.

[11] Hasan R, Khan MM, Ashek A, Rumpa IJ. Microcontroller Based Home Security System with GSM Technology. Open Journal of Safety Science and Technology. 2015;5(02):55.

[12] Amanullah M. Microcontroller based reprogrammable digital door lock security system by using keypad \& GSM/CDMA technology. IOSR Journal of electrical and Electronics Engineering (IOSR-JEEE). 2013;4(6):38-42.

[13] Chowdhury ZI, Imtiaz MH, Azam MM, Sumi MRA, Nur NS, editors. Design and implementation of pyroelectric infrared sensor based security system using microcontroller. IEEE Technology Students' Symposium; 2011: IEEE.

[14] Coorporation A. Atmel atmega328p datasheet. ed; 2011.

[15] Amadi DN and Triono J., "Smart Home Development For Home Security With Android Based," International Journal of Advanced Research in Computer Science, vol. 8(9), 2017.

[16] Fossas E. and Olivar G., "Study of chaos in the buck converter," IEEE Transactions on Circuits and Systems I: Fundamental Theory and Applications, vol. 43(1), pp. 13-25, 1996.

[17] Schelle D. and Castorena J., Buck-converter design demystified. Power Electronics Technology, 2006.

[18] Delgado AR, Picking R, and Grout V., Remote-controlled home automation systems with different network technologies. 2006.

[19] Zeyad M., Biswas P., Iqbal MZ, Ghosh S., and Biswas P., "Designing of Microcontroller Based Home Appliances Governor Circuits," Journal of Networks, vol. 3(2), pp. 58-63, 2018.

[20] Braginsky VB, Mitrofanov V, and Panov VI., Systems with small dissipation. University of Chicago Press, 1985

\section{BIOGRAPHIES OF AUTHORS}

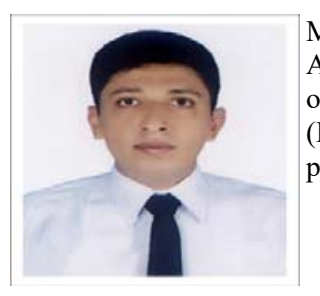

Mohammad Zeyad received his BSc in Electrical and Electronic Engineering degree from American International University-Bangladesh (AIUB) in 2017 with a concentration in the field of Power Electronics. His area of interest is in Power Electronics Engineering, Internet of Things (IoT), Biomedical Engineering, Wireless Communication, Microcontroller based system, signal processing etc. (mohammadzeyad.aiub@gmail.com)

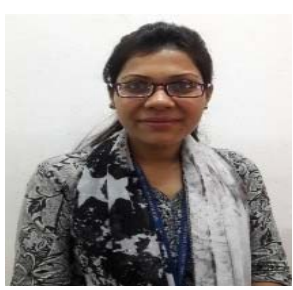

Susmita Ghosh obtained her BSc degree in EEE (2011) and MEng degree in MTEL (2013), Faculty of Engineering from American International University-Bangladesh (AIUB). Currently she is working as Assistant Professor in AIUB under the department of EEE, Faculty of Engineering. Her research interests are in the field of Power System Analysis, Renewable Energy and Smart Transportation System. (susmitaghosh29@gmail.com)

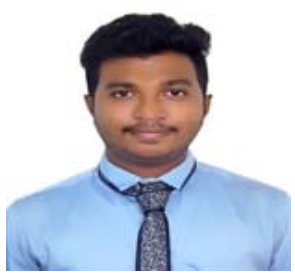

S.M. Masum Ahmed received his Bachelor of Science in Electrical \& Electronic Engineering degree from American International University-Bangladesh in 2018 with concentration in field of Renewable Energy. His area of interest is in Renewable Energy (Concentrated Solar power and Solar PV), Power Engineering (Micro-Grid \& Power System Protection), Power Electronics, Internet of Things (IoT), VHDL and Microcontroller based system. (masum.ahmed.aiub@gmail.com) 